\title{
ACE-FTS observations of acetonitrile in the lower stratosphere
}

\author{
J. J. Harrison ${ }^{1}$ and P. F. Bernath ${ }^{1,2}$ \\ ${ }^{1}$ Department of Chemistry, University of York, Heslington, York, YO10 5DD, UK \\ ${ }^{2}$ Department of Chemistry and Biochemistry, Old Dominion University, Norfolk, Virginia 23529, USA \\ Correspondence to: J. J. Harrison (jeremy.harrison@york.ac.uk)
}

Received: 5 December 2012 - Published in Atmos. Chem. Phys. Discuss.: 4 February 2013

Revised: 21 June 2013 - Accepted: 24 June 2013 - Published: 2 August 2013

\begin{abstract}
This work reports the first infrared satellite remote-sensing measurements of acetonitrile $\left(\mathrm{CH}_{3} \mathrm{CN}\right)$ in the Earth's atmosphere using solar occultation measurements made by the Atmospheric Chemistry Experiment Fourier transform spectrometer (ACE-FTS) between 2004 and 2011. The retrieval scheme uses new quantitative laboratory spectroscopic measurements of acetonitrile (Harrison and Bernath, 2012). Although individual ACE-FTS profile measurements are dominated by measurement noise, median profiles in $10^{\circ}$ latitude bins show a steady decline in volume mixing ratio from $\sim 150 \mathrm{ppt}$ (parts per trillion) at $11.5 \mathrm{~km}$ to $<40 \mathrm{ppt}$ at $25.5-29.5 \mathrm{~km}$. These new measurements agree well with the scant available air- and balloon-borne data in the lower stratosphere. An acetonitrile stratospheric lifetime of $73 \pm 20 \mathrm{yr}$ has been determined.
\end{abstract}

\section{Introduction}

Acetonitrile $\left(\mathrm{CH}_{3} \mathrm{CN}\right)$, also known as methyl cyanide, is a minor constituent of the Earth's atmosphere. Biomass burning is the dominant source (up to 90-95\%) of acetonitrile emissions (de Gouw et al., 2003; Singh et al., 2003; Li et al., 2003), with ocean uptake believed to be the dominant sink. Chemical loss is primarily through the reaction with the hydroxyl radical, which is rather slow; this is the dominant sink in the stratosphere. The total atmospheric lifetime of acetonitrile is in the order of six months (Singh et al., 2003; Li et al., 2003), making this molecule a useful tracer for biomass burning. In situ observations of tropospheric acetonitrile (Singh et al., 2003) have indicated typical background levels of 50$200 \mathrm{ppt}$ (parts per trillion). In regions of forest fire activity, tropospheric mixing ratios are significantly enhanced (de Gouw et al., 2003).
Early in situ measurements of acetonitrile are somewhat contradictory, and significantly lower than more recent measurements; see Schneider et al. (1997) for an in depth discussion. A number of early studies made use of the ionmolecule reaction mass spectrometry (IMRMS) technique, in which the detection relies on the ion-molecule reaction in which a $\mathrm{CH}_{3} \mathrm{CN}$ molecule displaces one water ligand from a hydrated $\mathrm{H}^{+}\left(\mathrm{H}_{2} \mathrm{O}\right)_{n}$ cluster. Unfortunately, the reverse reaction becomes more efficient at higher water vapour abundance and ion hydration, which increases with relative humidity. For this reason it is expected that IMRMS measurements in the troposphere and near the tropopause will be underestimated (Schneider et al., 1997), but not measurements in the stratosphere. Comparisons with these early measurements need to be made with care. More recent in situ techniques used to measure acetonitrile abundances, including proton-transfer-reaction mass spectrometry (de Gouw et al., 2003) and gas chromatography (Singh et al., 2003), are more robust.

Knowledge of the global acetonitrile budget is incomplete and not well constrained (Singh et al., 2003). For example, there is uncertainty in the role played by the ocean. Sanhueza et al. (2004) suggest that the ocean acts as an acetonitrile reservoir; perhaps gas-phase acetonitrile dissolves in cold seawater and is released back into the atmosphere by warm, tropical seawater.

It is difficult to address these problems because there are very few in situ data currently available on the atmospheric distribution of acetonitrile, and even less oceanic data. However, the recent ability of satellite instruments to take global measurements of acetonitrile holds great promise to provide better quantification of the global budget. The first satellite measurements of acetonitrile in the Earth's atmosphere were taken in the 1990 s by the Microwave Limb Sounder 
(MLS) instrument on the Upper Atmosphere Research Satellite (UARS) (Livesey et al., 2001, 2004). More recently, acetonitrile has been observed by the MLS instrument on the Aura satellite (version 2.2 data product) in biomass-burning plumes associated with the large bush fires which occurred in southeast Australia in February 2009 (Pumphrey et al., 2011); a new version 3.3 MLS acetonitrile data product is now available. The first infrared remote sensing measurements of acetonitrile were taken by the balloon-borne MkIV interferometer; atmospheric profiles were retrieved from solar occultation spectra recorded for 12 balloon flights between 1993 and 2004 (Kleinböhl et al., 2005).

This work presents the first infrared remote sensing measurements of acetonitrile from orbit; these are used to provide the first near-global distribution of acetonitrile in the lower stratosphere, and an estimate of the stratospheric lifetime.

\section{Infrared spectroscopy of acetonitrile}

Retrieving concentration profiles from infrared atmospheric spectra recorded by satellite-borne instruments requires accurate laboratory spectroscopic measurements covering the appropriate range of atmospheric temperatures and pressures, and recorded at a sufficient resolution, determined by the Doppler or pressure broadening, to resolve all the molecular features. Until recently, the only available $\mathrm{CH}_{3} \mathrm{CN} /$ synthetic dry air infrared cross sections were limited to three low-resolution $\left(0.1125 \mathrm{~cm}^{-1}\right)$ composite spectra over the region $600-6500 \mathrm{~cm}^{-1}$ (Rinsland et al., 2005), with sample temperatures 276,298 , and $323 \mathrm{~K}$ and pressures made up to 760 Torr with $\mathrm{N}_{2}$ as broadening gas. Despite not extending over the range of temperatures and pressures found in the upper troposphere/lower stratosphere (UTLS) and having been recorded at low resolution (and due to the lack of any alternatives), these spectra were used to derive a pseudo-linelist between 870 and $1650 \mathrm{~cm}^{-1}$, which was used to retrieve atmospheric profiles of $\mathrm{CH}_{3} \mathrm{CN}$ from solar occultation spectra recorded by the MkIV balloon-borne interferometer (Kleinböhl et al., 2005). (Note that pseudolines are "effective" spectral lines that empirically reproduce the pressure- and temperature-dependencies of spectral absorption.) By their very nature, these pseudo-lines must extrapolate to lower temperatures and pressures; the errors in these lines are determined by the assumptions made for the pressure-broadening and pressure-shift parameters, and the partition function. This extrapolation undoubtedly contributes to the overall acetonitrile retrieval error in this previous study.

Recently, a set of high-resolution $\left(0.015 \mathrm{~cm}^{-1}\right)$ infrared absorption cross sections for acetonitrile/synthetic dry air in the $880-1700 \mathrm{~cm}^{-1}$ spectral region (Harrison and Bernath, 2012) has been made available to the remote-sensing community; this dataset is included in the recent HITRAN2012 compilation (www.hitran.com). The cross sections cover a number of temperatures between 203 and $297 \mathrm{~K}$ and air-broadening pressures appropriate for UTLS conditions. These are the only low temperature quantitative measurements available for atmospheric remote-sensing purposes. Experimentally, these measurements are difficult due to the low vapour pressure of acetonitrile at low temperatures and the requirement for long optical pathlengths to achieve sufficient signal-to-noise ratios.

\section{Retrieval of acetonitrile from ACE-FTS spectra}

The ACE-FTS instrument, which covers the spectral region $750-4400 \mathrm{~cm}^{-1}$ with a resolution of $0.02 \mathrm{~cm}^{-1}$, uses the sun as a light source to record atmospheric limb spectra during sunrise and sunset ("solar occultation"). Transmittance spectra are obtained by ratioing against exoatmospheric solar spectra measured during each orbit. These spectra, with high signal-to-noise ratios, are recorded through long atmospheric limb paths ( $\sim 300 \mathrm{~km}$ effective length), thus providing a low detection threshold for trace species. ACE has an excellent vertical resolution of about $2-3 \mathrm{~km}$ in the troposphere and can measure up to 30 occultations per day, with each occultation sampling the atmosphere from $150 \mathrm{~km}$ down to the cloud tops (or $5 \mathrm{~km}$ in the absence of clouds). The locations of ACE occultations are dictated by the low Earth circular orbit of the SCISAT-1 satellite and the relative position of the sun. Over the course of a year, the ACE-FTS records atmospheric spectra over a large portion of the globe (Bernath et al., 2005).

Version 3.0 of the ACE-FTS retrieval software was used for the $\mathrm{CH}_{3} \mathrm{CN}$ VMR (volume mixing ratio) retrievals. Vertical profiles of trace gases (along with temperature and pressure) are derived from the recorded transmittance spectra via a nonlinear least squares global fit to the selected spectral region(s) for all measurements within the altitude range of interest. $\mathrm{CH}_{3} \mathrm{CN}$ retrievals were performed using a microwindow from 1462.96 to $1463.60 \mathrm{~cm}^{-1}$, with atmospheric pressure and temperature profiles, and the tangent heights of the measurements taken from the v3.0 processing of the ACEFTS data. The abundance of molecules with absorption features in the microwindow $\left(\mathrm{CH}_{4},{ }^{13} \mathrm{CH}_{4}, \mathrm{CH}_{3} \mathrm{D}, \mathrm{H}_{2} \mathrm{O}, \mathrm{H}_{2}^{18} \mathrm{O}\right.$, $\mathrm{H}_{2}^{17} \mathrm{O}, \mathrm{HDO}, \mathrm{O}_{3}, \mathrm{C}_{2} \mathrm{H}_{6}, \mathrm{HCN}$ ) were adjusted simultaneously with the $\mathrm{CH}_{3} \mathrm{CN}$ amount. Spectroscopic line parameters for most molecules were taken from the HITRAN 2004 database (Rothman et al., 2005), except for $\mathrm{CH}_{3} \mathrm{CN}$ (see Sect. 2), $\mathrm{C}_{2} \mathrm{H}_{6}$ (Di Lauro et al., 2012), and some of the $\mathrm{CH}_{4}$ line parameters (Kleinböhl et al., 2005).

The lower altitude of the $\mathrm{CH}_{3} \mathrm{CN}$ retrieval is limited by the saturation at low altitudes of water vapour spectral lines close to the chosen microwindow, in particular the strong line at $1464.90506 \mathrm{~cm}^{-1}$. This limit was chosen as 13$2 \sin ^{2}\left(\right.$ latitude $\left.^{\circ}\right) \mathrm{km}$, a phenomenological expression reflecting the observation that ACE-FTS spectra were unusable below $11 \mathrm{~km}$ at the poles and below $13 \mathrm{~km}$ at the Equator. Furthermore, a quadratic baseline term was added to the forward 


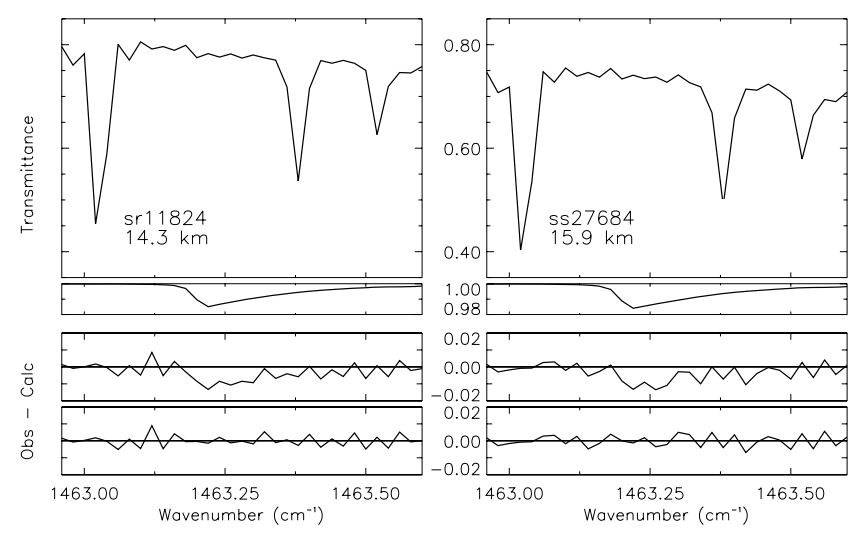

Fig. 1. The retrieval microwindows for ACE-FTS occultations sr11824 and ss27684. The top panels show the transmittance spectra at tangent heights of 14.3 and $15.9 \mathrm{~km}$, respectively. The second panels reveal the calculated contribution to each measurement based on the retrieved VMR $(<2 \%)$. The third panels give the observed-calculated residuals for both retrievals without the inclusion of acetonitrile in the forward model. The bottom panels contain the observed-calculated residuals.

model to minimise residuals arising from non-Voigt lineshape of the water lines; such an approach was deemed satisfactory for the narrow microwindow chosen. The upper altitude was set at $30-5 \sin ^{2}\left(\right.$ latitude $\left.{ }^{\circ}\right) \mathrm{km}$, accounting for the fact that non-zero $\mathrm{CH}_{3} \mathrm{CN}$ VMRs extend to higher altitudes in the tropical region.

Two ACE-FTS transmittance spectra are plotted in the top panels in Fig. 1. The first of these comes from occultation sr11824 (recorded on 23 October 2005 west of Cape Verde, off the coast of Western Africa) at a tangent height of $14.3 \mathrm{~km}$; the second from occultation ss 27684 (recorded on 3 October 2008 over the Pacific Ocean, $\sim 100 \mathrm{~km}$ east of Christchurch, New Zealand) at a tangent height of $15.9 \mathrm{~km}$. The three strong lines clearly observed are due to absorption of $\mathrm{CH}_{4}$. The second panels reveal the calculated contribution to each measurement based on the retrieved VMR $(<2 \%)$. The third panels give the observed-calculated residuals for both retrievals without the inclusion of acetonitrile in the forward model; the shape of these residuals matches well with the calculated acetonitrile contribution. The bottom panels contain the observed-calculated residuals, indicating the goodness of the fit.

\section{Retrieval errors}

For a single ACE profile, the $1 \sigma$ statistical fitting errors at each altitude are comparable to the magnitude of the retrieved $\mathrm{CH}_{3} \mathrm{CN}$ VMRs. Such errors are random in nature and are largely determined by the measured signal-to-noise ratios of the ACE-FTS spectra, i.e. measurement noise. There are a number of reasons for this large random error contribution.
The retrieval relies on one sharp, narrow feature (the ${ }^{r} Q_{0}$ branch of the $v_{6}$ band) in the acetonitrile infrared spectrum, located within the $1462.96-1463.60 \mathrm{~cm}^{-1}$ microwindow. This is the strongest feature in the spectrum, and the only feature appropriate for quantitative analysis.

Whereas the large measurement noise prevents meaningful comparisons between single VMR profiles, comparisons are possible between suitable sets of average or median profiles. In this work, the median statistic is preferred because it is less sensitive to extreme VMR outliers. For filtered median profiles, such as those described in the following section, the random errors become small and the systematic errors dominate. In previous ACE-FTS data studies, systematic errors have been determined by perturbing various parameters in turn (e.g. retrieved altitude and temperature) by their $1 \sigma$ uncertainties and re-running the retrieval for small subsets of occultations. For the present case, it would be necessary to process thousands of occultations in such a way, then average them in order to reduce the random error contribution. Instead of using this approach, which is time consuming, it was decided to estimate the systematic errors on the basis of similar studies for methanol (Dufour et al., 2006), formic acid (González Abad et al., 2009), and PAN (peroxyacetyl nitrate) (Tereszchuk et al., 2013).

Spectroscopic sources of systematic error predominantly arise from the acetonitrile absorption cross sections $(\sim 6 \%)$, with minor contributions from interfering species in the microwindow, $\mathrm{CH}_{4}$ and $\mathrm{H}_{2} \mathrm{O}$. Kleinböhl et al. (2005) attributed errors of 2.5 and $1 \%$ to $\mathrm{CH}_{4}$ and $\mathrm{H}_{2} \mathrm{O}$, respectively, to the MkIV acetonitrile retrievals. The ACE-FTS microwindow is narrower than used in the previous work, making use of fewer $\mathrm{CH}_{4}$ lines; in the present case, the contribution due to poor $\mathrm{CH}_{4}$ line parameters is likely closer to $\sim 1 \%$. The addition of a quadratic baseline term and the use of a narrow microwindow are expected to minimise errors associated with bad residuals near the wing of the strong $\mathrm{H}_{2} \mathrm{O}$ line at $1464.90506 \mathrm{~cm}^{-1}$; an uncertainty $\sim 0.5 \%$ is anticipated. Note that using a narrower microwindow increases the uncertainty in the spectral baseline slightly, but this simply contributes to the random error of the retrieval. Additional sources of systematic error arise from pointing (tangent height $1 \sigma$ uncertainty of $150 \mathrm{~m})$, temperature $(1 \sigma$ uncertainty of $2 \mathrm{~K}$ ) and instrumental line shape (ILS; $5 \%$ perturbation in field of view). It is expected that pointing and temperature errors are $\sim 10 \%$ each at most, with ILS errors $\sim 2 \%$. Taking the square root of the sum of these squared $1 \sigma$ uncertainties gives an overall systematic error of $\sim 16 \%$.

\section{Global distribution and vertical profiles}

The large random error contribution to the retrieved $\mathrm{CH}_{3} \mathrm{CN}$ VMRs (Sect. 4) and the limited global coverage of the ACEFTS instrument (a maximum of 30 measurements per day, and most of these at high latitudes) make it very difficult to 

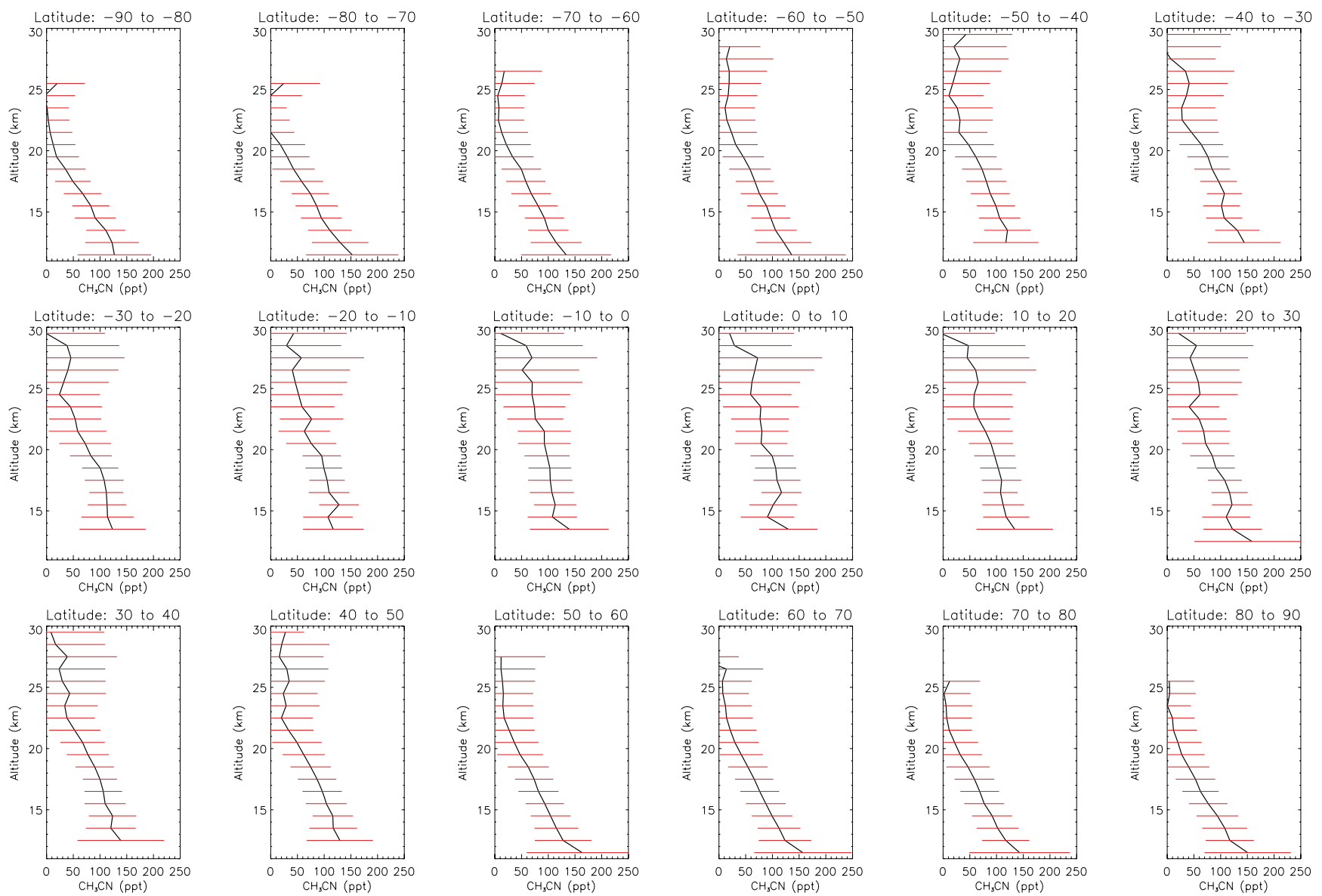

Fig. 2. Median $\mathrm{ACE} \mathrm{CH}_{3} \mathrm{CN}$ profiles in $10^{\circ}$ latitude bins for the complete time period of the available ACE measurements (2004-2011), after filtering out occultations that sample biomass burning plumes, occultations located inside or on the edge of a polar vortex, and significant VMR outliers. Errors at each altitude are taken as one MAD of the VMR distribution for the filtered dataset.

quantify the $\mathrm{CH}_{3} \mathrm{CN}$ variability due to biomass burning; occasionally the ACE-FTS directly samples biomass burning plumes. As a result, this work focuses only on acetonitrile background concentrations.

In total 26938 ACE occultations between 2004 and 2011 were processed. In order to obtain global distributions indicative of background concentrations, these were filtered to remove 3430 occultations that sample biomass burning plumes using the criterion established by Tereszchuk et al. (2011). Briefly, any occultation with enhanced tropospheric hydrogen cyanide $(\mathrm{HCN})$ concentrations $(\geq 350 \mathrm{ppt})$ relative to the background (typically $\sim 225-250 \mathrm{ppt}$ ) was considered to have sampled a plume. HCN is particularly suitable for this purpose because it is emitted almost entirely from biomass burning and has an atmospheric lifetime of $\sim$ five months.

The remaining occultations were then classified using scaled potential vorticities and equivalent latitude-vortex edge distances from ACE derived meteorological products (DMPs) (Manney et al., 2007) in a similar approach to that adopted by Nassar et al. (2005); 6625 occultations located inside or on the edge of a polar vortex were removed from the dataset. Such occultations have perturbed profiles due to the significant diabatic descent of air. The SCISAT- 1 orbit results in a large number of occultations at high latitudes, and discarding a number of these has no detrimental effect on global sampling. The remaining 16883 "extravortex" occultations were filtered to remove significant outliers.

Median $\mathrm{ACE} \mathrm{CH}_{3} \mathrm{CN}$ profiles were determined in $10^{\circ}$ latitude bins for these 16883 occultations (see Fig. 2). Plots for individual years indicate that any inter-annual variability is well within the error bars. Therefore all data were plotted together, thus reducing the random noise contribution to the profiles. The 18 latitude bins from -90 to $90^{\circ}$ contain $224,412,2736,1463,687,417,325,321,336,352,295$, $307,466,891,1780,3827,1309$ and 735 occultations, respectively, illustrating the uneven distribution of data, with about $40 \%$ lying in five of the latitude bins $\left(-70\right.$ to $-50^{\circ}$, and 50 to $80^{\circ}$ ). Errors at each altitude are taken as one median absolute deviation (MAD) of the VMR distribution for the filtered dataset. (For a dataset, the MAD is defined as the median of the absolute deviations from the data's median. It measures the spread of values within a dataset but 

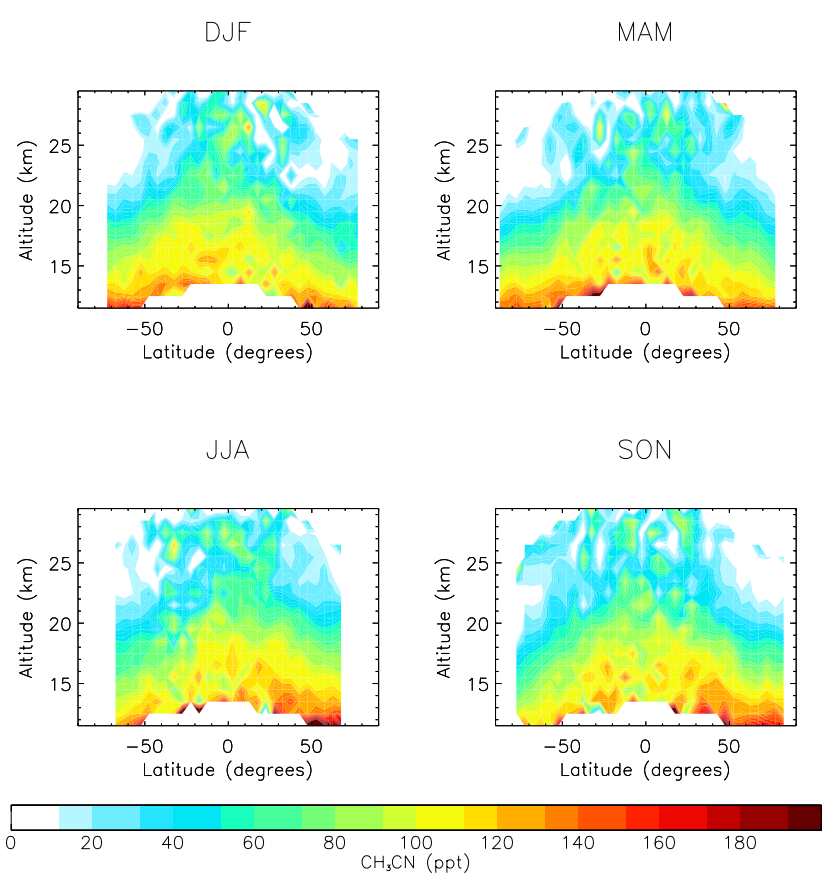

Fig. 3. Altitude-latitude cross sections for the four "seasons" DJF, MAM, JJA and SON. ACE-FTS VMRs used are the averages of all filtered data at each altitude within $5^{\circ}$ latitude bins.

with outliers given less weighting than they are when using the standard deviation.) The distribution of acetonitrile VMRs in each bin at each altitude is approximately random (Gaussian). All the profiles in Fig. 2 show median VMRs between 110 and $160 \mathrm{ppt}$ at the lowest altitudes, which decrease as altitude increases. This drop-off with altitude occurs more rapidly in the high-latitude/polar regions, with acetonitrile VMRs dropping to zero by $\sim 25 \mathrm{~km}$. In the midlatitude/tropical regions, acetonitrile still persists in small quantities $(\sim 50 \mathrm{ppt})$ at the top of the retrieval range $(30 \mathrm{~km})$. This reflects the larger acetonitrile concentrations near the equator, where biomass burning activity is most prevalent, and the large-scale circulation of air around the globe, in which tropospheric air ascends into the stratosphere over the tropics and descends into the troposphere towards the poles.

Altitude-latitude cross sections are plotted in Fig. 3 for the four "seasons", DJF (December, January, February), MAM (March, April, May), JJA (June, July, August) and SON (September, October, November). ACE-FTS VMRs used are the averages of all filtered data at each altitude within $5^{\circ}$ latitude bins. The slight hemispherical asymmetry in the plots points to a small seasonal variation in acetonitrile background concentrations. In particular, there are slightly higher background levels in the Southern Hemisphere during December to May, and slightly higher levels in the Northern Hemisphere from July to November. This seasonal variability is believed to result from seasonal biomass burning contributions coupled with the six-month atmospheric lifetime.
$\mathrm{CH}_{3} \mathrm{CN}$ measurements below $11 \mathrm{~km}$ at the poles and below $13 \mathrm{~km}$ at the Equator would allow firmer conclusions to be drawn, however, as mentioned earlier, the retrieval is limited by the saturation of a nearby spectral line of water at these altitudes. Note that most of the measurements plotted in Fig. 3 are above the tropopause, apart from those for the lowest few kilometres near the tropics, which are below. The position of the tropopause can vary slightly between different measurements within the same latitude band.

\section{Comparison with other measurements}

There are no airborne measurements of acetonitrile near the tropopause or in the lower stratosphere that can be used to provide a true validation of the ACE-FTS measurements. However, several datasets are available that can provide a useful consistency check. Mass-spectrometric measurements in the lower stratosphere were made as part of the STREAM project (Stratosphere-Troposphere Experiment by Aircraft Measurements), during the SESAME (Second European Stratospheric Arctic and Midlatitude Experiment) campaign (Schneider et al., 1997). The flights took place over northern Scandinavia on 9, 18, 21, and 24 February 1995, covering heights up to $12.8 \mathrm{~km}$ and latitudes between 62 and $73^{\circ} \mathrm{N}$. Gas-chromatographic measurements were made during the TRACE-P (Transport and Chemical Evolution over the Pacific) campaign (25 February to 10 April 2001) over the Pacific troposphere from 0.1 to $12 \mathrm{~km}$ over a region that extended from 10 to $45^{\circ} \mathrm{N}$ latitude (Singh et al., 2003). As discussed in Sect. 5, ACE acetonitrile measurements show very little variation from year to year. Thus, a comparison with airborne measurements taken over different time periods is still useful. In Fig. 4 TRACE-P data in the upper troposphere (10$12 \mathrm{~km}$ ), taken directly from Fig. 2 of Singh et al. (2003), and STREAM data in the lower stratosphere, taken directly from Fig. 3 of Schneider et al. (1997) (with appropriate adjustment of the altitude scale) are each compared with a median ACE profile over the appropriate latitude range. If ACE VMRs are extrapolated to the altitudes of the airborne measurements, the agreement between datasets is rather good.

Figure 4 also contains a comparison of the average of six MkIV profiles between 33 and 36 $\mathrm{N}$ (1993-1996 and 20032004), taken directly from Fig. 2 of Kleinböhl et al. (2005), with a median ACE profile over the same latitude range. Although the two profiles agree within experimental error, the VMRs for each dataset drop off at different rates with increasing altitude. It is possible that the MkIV retrievals are subject to a small altitude-dependent bias arising from the use of pseudo-lines and the associated errors in extrapolating to low atmospheric temperatures and pressures from a set of spectra recorded at relatively high temperatures and pressures.

As mentioned in the introduction, the only previous satellite measurements of acetonitrile in the atmosphere come 

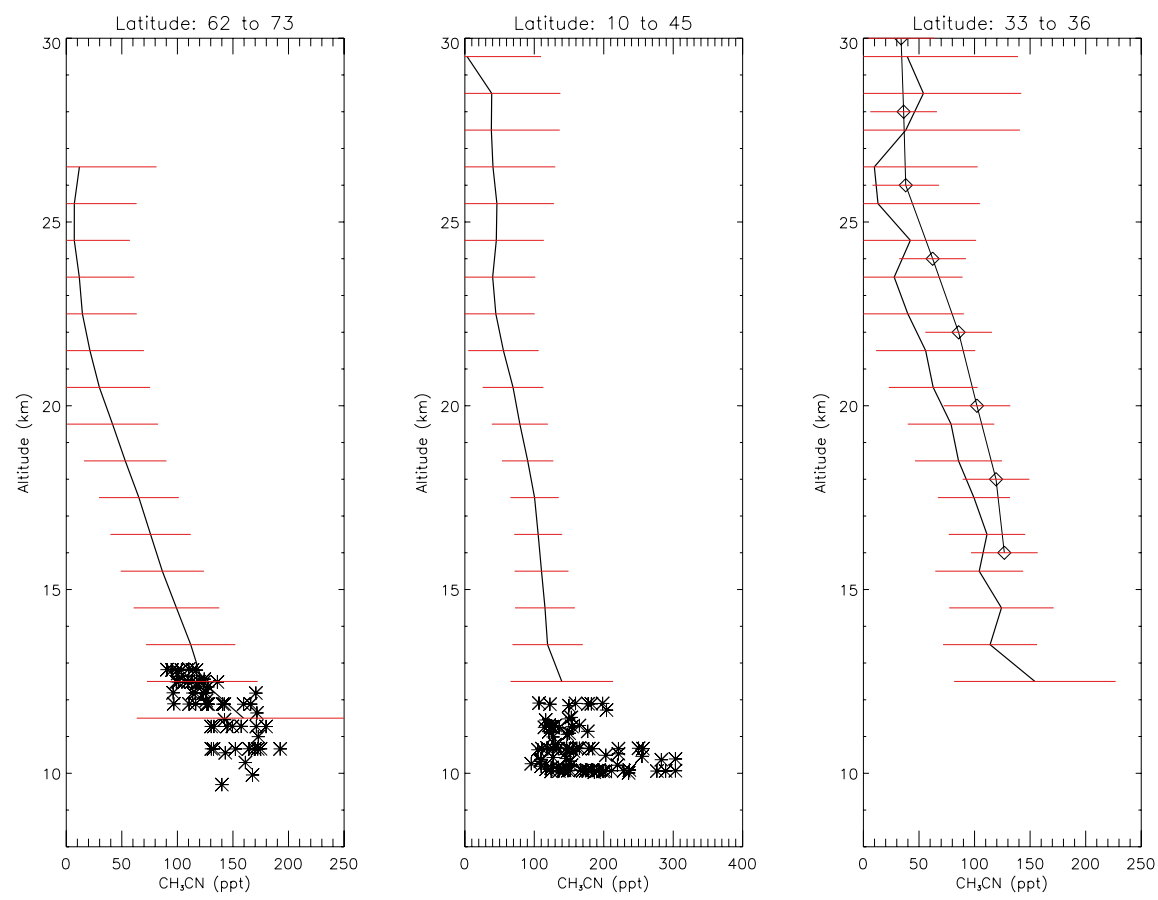

Fig. 4. Left: STREAM data in the lower stratosphere at latitudes between 62 and $73^{\circ} \mathrm{N}$, taken directly from Fig. 3 of Schneider et al. (1997), superimposed on a median ACE profile over the same latitude range. Middle: TRACE-P data in the upper troposphere (10-12 km) over the latitude range $10-45^{\circ} \mathrm{N}$, taken directly from Fig. 2 of Singh et al. (2003), superimposed on a median ACE profile over the same latitude range. Right: The average of six MkIV profiles between 33 and 36 ${ }^{\circ} \mathrm{N}$ (1993-1996 and 2003-2004), taken directly from Fig. 2 of Kleinböhl et al. (2005), superimposed on a median ACE profile over the same latitude range.

from the MLS instruments on UARS and Aura. The first MLS-UARS measurements (Livesey et al., 2001) in the stratosphere $(\sim 20$ to $\sim 50 \mathrm{~km})$ from the 1990 s do not exceed 50-60 ppt; peak values of 50-60 ppt were observed exclusively in the tropical stratosphere around $\sim 25-30 \mathrm{~km}$. To explain this persistent peak in the tropical profiles, the authors suggested a stratospheric source of $\mathrm{CH}_{3} \mathrm{CN}$ in the tropics. Inspection of the tropical ACE-FTS profiles in Fig. 2 provides no evidence for a stratospheric source. This seems to indicate retrieval errors in the earlier MLS work.

The v2.2 MLS-Aura $\mathrm{CH}_{3} \mathrm{CN}$ data product, derived from radiances measured by the radiometer centred near $190 \mathrm{GHz}$, was not recommended for use in scientific studies. However the latest v3.3 product, using measurements from the $640 \mathrm{GHz}$ radiometer, is considered to be of better quality and reliability. Although these data have never been validated, only those measurements over the altitude range 46$1.0 \mathrm{hPa}(\sim 20-50 \mathrm{~km})$ are recommended for scientific studies (except in the winter polar vortex regions) (Livesey et al., 2011). Preliminary comparisons with results from a twodimensional chemistry transport model indicate that the v3.3 VMRs are biased substantially high in the lower stratosphere (147-68 hPa). A detailed comparison with ACE-FTS data below $\sim 20 \mathrm{~km}$ is, therefore, rather meaningless.
The v3.3 MLS $\mathrm{CH}_{3} \mathrm{CN}$ measurements do not feature the $\sim 25-30 \mathrm{~km}$ peak in the tropical profiles, however they appear to be biased higher than ACE and MkIV, particularly at the lower end of the common altitude range $(\sim 20-30 \mathrm{~km})$. Figure 3.4.2 of the EOS MLS v3.3 Level 2 data quality and description document provides a plot of ensemble mean v3.3 profiles in the latitude range $50^{\circ} \mathrm{S}-50^{\circ} \mathrm{N}$ averaged over 30 days in April 2008. This plot indicates VMRs of $\sim 150 \mathrm{ppt}$ at $46 \mathrm{hPa}(\sim 20 \mathrm{~km})$ and $\sim 100 \mathrm{ppt}$ at $32 \mathrm{hPa}(\sim 25 \mathrm{~km})$; over this latitude range the ACE-FTS VMRs are smaller. Figure 3.4.3 in the same document provides v3.3 monthly zonal means for January and July 2007, indicating VMRs of $\sim 160-180 \mathrm{ppt}$ at $46 \mathrm{hPa}(\sim 20 \mathrm{~km})$, and $\sim 120-140 \mathrm{ppt}$ at $32 \mathrm{hPa}(\sim 25 \mathrm{~km})$ in tropical regions. Again, a comparison to ACE-FTS data in Fig. 2 indicates that this MLS data are biased too high. This preliminary comparison suggests that the v3.3 VMRs are biased over a larger altitude range than just $147-68 \mathrm{hPa}$, the range acknowledged in the aforementioned document. Until this MLS retrieval scheme is revisited, a full validation of the ACE-FTS data cannot be carried out. 


\section{Stratospheric lifetime}

The decrease in acetonitrile VMR from 160 to 110 ppt measured by Schneider et al. (1997) between 1.0 and $4.2 \mathrm{~km}$ above the tropopause led them to conclude that the stratospheric lifetime of $\mathrm{CH}_{3} \mathrm{CN}$ is about $1 \mathrm{yr}$, shorter than previously thought. To explain this they suggested an additional stratospheric sink, perhaps the ion-catalysed conversion of $\mathrm{CH}_{3} \mathrm{CN}$ to $\mathrm{HCN}$. Kleinböhl et al. (2005) later concluded from MkIV profile measurements that the lifetime in the lower stratosphere is about $10-20 \mathrm{yr}$, that the proposed ionmolecule reactions do not play a major role in acetonitrile loss processes, and that the gas-phase loss mechanisms are fully adequate to explain the abundance of $\mathrm{CH}_{3} \mathrm{CN}$ in the stratosphere.

In order to estimate the stratospheric lifetime of acetonitrile from ACE-FTS measurements, the method of Plumb and Ko (1992) is used. Stratospheric species with lifetimes long compared to horizontal and vertical transport timescales are linearly correlated in the lower stratosphere according to the equation

$\frac{\tau_{1}}{\tau_{2}} \cong \frac{\mathrm{d} \sigma_{2}}{\mathrm{~d} \sigma_{1}} \frac{\sigma_{1}}{\sigma_{2}}$,

where $\tau_{1}$ and $\tau_{2}$ are the stratospheric lifetimes of species 1 and 2 respectively, $\sigma_{1}$ and $\sigma_{2}$ are their mixing ratios (representative of tropospheric concentrations), and $\mathrm{d} \sigma_{2} / \mathrm{d} \sigma_{1}$ is the gradient of their linear correlation. Since reaction with $\mathrm{OH}$ is the principal stratospheric sink of acetonitrile and since this reaction is rather slow (Singh et al., 2003), it is expected to have a comparatively long lifetime.

ACE observations of $\mathrm{CH}_{3} \mathrm{CN}$ and $\mathrm{CFC}-11$, a chlorofluorocarbon with a stratospheric lifetime of $56 \mathrm{yr}$ (Douglass et al., 2008), associated with the 16883 filtered occultation measurements were used for this correlation. In order to minimise the random error contribution associated with the $\mathrm{CH}_{3} \mathrm{CN}$ VMRs and to remove the effects of the ACE-FTS highlatitude sampling bias, data were binned in $10^{\circ}$ latitude increments; the median VMRs in each bin were plotted against each other, with errors given as \pm 1.0 MAD of these median values. ACE-FTS data within the latitude ranges $30-90^{\circ} \mathrm{S}$ and $30-90^{\circ} \mathrm{N}$ and altitude range $13.5-24.5 \mathrm{~km}$, i.e. excluding data from the tropics (Volk et al., 1997), are plotted in Fig. 5, revealing a clear correlation between $\mathrm{CH}_{3} \mathrm{CN}$ and $\mathrm{CFC}-11$ VMRs. (For the sake of clarity, error bars are not included in the plot.)

Since the lifetime of CFC-11 is well known, the linear correlation can be used to estimate the stratospheric lifetime of acetonitrile. Note that the VMRs of CFC-11 have slowly decreased in the stratosphere by $\sim 6 \%$ from 2004 to 2011 (Brown et al., 2011); the value of $\sigma_{\mathrm{CFC}-11}$ was taken as the average ( $245.15 \mathrm{ppt}$ ) of the $2007 / 2008$ annual mean mole fractions in Table 1-1 of the WMO report (Montzka et al., 2011). The error introduced into the calculation by this approximation is deemed minor compared to other error sources, the

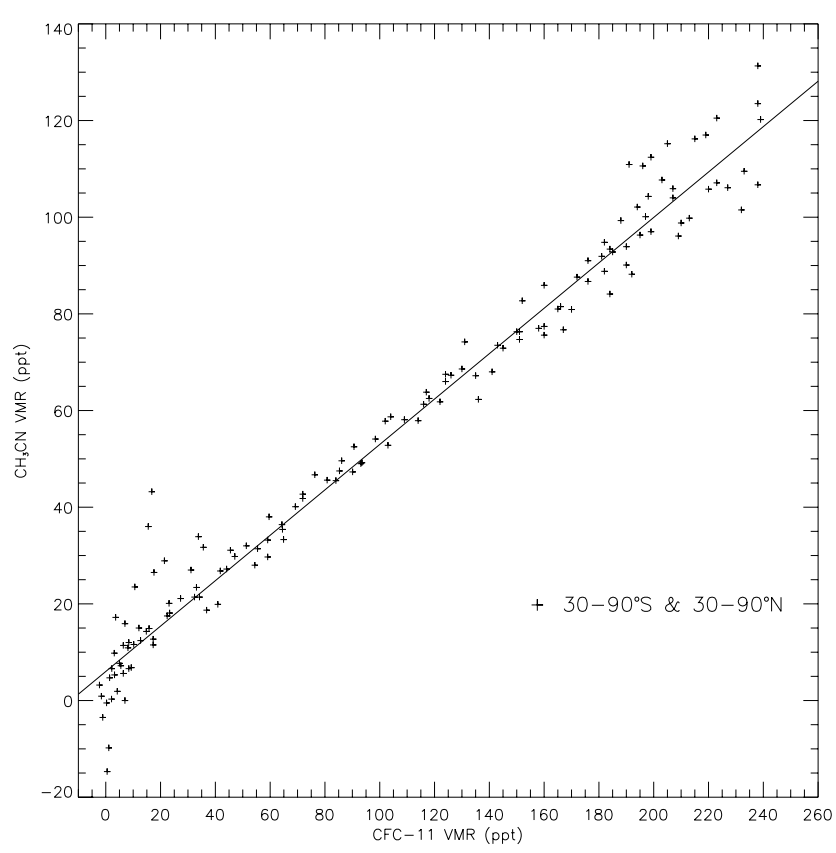

Fig. 5. Linear correlation between $\mathrm{CH}_{3} \mathrm{CN}$ and CFC-11 ACE-FTS data (in $10^{\circ}$ latitude bins) in the extratropical regions $\left(30-90^{\circ} \mathrm{S}\right.$ and $\left.30-90^{\circ} \mathrm{N} ; 13.5-24.5 \mathrm{~km}\right)$.

largest being the $\mathrm{CH}_{3} \mathrm{CN}$ VMRs. The value of $\sigma_{\mathrm{CH} 3 \mathrm{CN}}$ is assumed to be $150 \mathrm{ppt}$. A linear regression appropriate for data with errors in both $x$ and $y$ was performed; a slope of 0.470 was obtained, from which a stratospheric lifetime of $73 \pm 20 \mathrm{yr}$ was derived, longer than the estimate of $\sim 10$ $20 \mathrm{yr}$ made by Kleinböhl et al. (2005). This long stratospheric lifetime indicates that the tropospheric lifetime of $\mathrm{CH}_{3} \mathrm{CN}$ is approximately equal to the total atmospheric lifetime of $\sim$ six months (Singh et al., 2003; Li et al., 2003). Note that in the event of the CFC-11 stratospheric lifetime being revised, the derived value of $73 \mathrm{yr}$ should be adjusted by a factor of (new CFC-11 lifetime)/56.

\section{Conclusions}

For the first time, infrared satellite remote-sensing measurements of acetonitrile have been taken in the Earth's atmosphere by the ACE-FTS instrument. The retrieval scheme uses new quantitative laboratory spectroscopic measurements of acetonitrile (Harrison and Bernath, 2012). These measurements have been used to determine the first global distribution of $\mathrm{CH}_{3} \mathrm{CN}$ in the lower stratosphere. Median ACE-FTS profiles in $10^{\circ}$ latitude bins show a steady decline in volume mixing ratio from $\sim 150 \mathrm{ppt}$ at $11.5 \mathrm{~km}$ to $<40 \mathrm{ppt}$ at $25.5-29.5 \mathrm{~km}$. Available air- and balloon-borne data in the lower stratosphere agree well with ACE-FTS measurements. An acetonitrile stratospheric lifetime of $73 \pm 20 \mathrm{yr}$ has been determined. 
Acknowledgements. The authors wish to thank the Natural Environment Research Council (NERC) for supporting J. J. Harrison through grants NE/I022663/1 and NE/F017391/1. The ACE satellite mission is funded primarily by the Canadian Space Agency (CSA). C. D. Boone is thanked for providing assistance with the ACE v3.0 retrieval software.

Edited by: P. Monks

\section{References}

Bernath, P. F., McElroy, C. T., Abrams, M. C., Boone, C. D., Butler, M., Camy-Peyret, C., Carleer, M., Clerbaux, C., Coheur, P.F., Colin, R., DeCola, P., DeMazi'ere, M., Drummond, J. R., Dufour, D., Evans, W. F. J., Fast, H., Fussen, D., Gilbert, K., Jennings, D.E., Llewellyn, E. J., Lowe, R. P., Mahieu, E., McConnell, J. C., McHugh, M., McLeod, S. D., Michaud, R., Midwinter, C., Nassar, R., Nichitiu, F., Nowlan, C., Rinsland, C. P., Rochon, Y. J., Rowlands, N., Semeniuk, K., Simon, P., Skelton, R., Sloan, J. J., Soucy, M.-A., Strong, K., Tremblay, P., Turnbull, D., Walker, K. A., Walkty, I., Wardle, D. A., Wehrle, V., Zander, R., and Zou, J.: Atmospheric Chemistry Experiment (ACE): Mission overview, Geophys. Res. Lett., 32, L15S01, doi:10.1029/2005GL022386, 2005.

Brown, A. T., Chipperfield, M. P., Boone, C., Wilson, C., Walker, K. A., Bernath, P. F.: Trends in atmospheric halogen containing gases since 2004, J. Quant. Spectrosc. Rad. Trans., 112, 25522566, 2011.

de Gouw, J. A., Warneke, C., Parrish, D. D., Holloway, J. S., Trainer, M., Fehsenfeld, F. C.: Emission sources and ocean uptake of aceotnitrile $\left(\mathrm{CH}_{3} \mathrm{CN}\right)$ in the atmosphere, J. Geophys. Res., 108, 4329, doi:10.1029/2002JD002897, 2003.

Di Lauro, C., Lattanzi, F., Brown, L. R., Sung, K., Vander Auwera, J., Mantz, A. W., Smith, M. A. H.: High resolution investigation of the $7 \mu \mathrm{m}$ region of the ethane spectrum, Planet. Space Sci., 60, 93-101, doi:10.1016/j.pss.2011.01.008, 2012.

Douglass, A. R., Stolarski, R. S., Schoeberl, M. R., Jackman, C. H., Gupta, M. L., Newman, P. A., Nielsen, J. E., and Fleming, E. L.: Relationship of loss, mean age of air and the distribution of CFCs to stratospheric circulation and implications for atmospheric lifetimes, J. Geophys. Res., 113, D14309, doi:10.1029/2007JD009575, 2008.

Dufour, G., Boone, C. D., Rinsland, C. P., and Bernath, P. F.: First space-borne measurements of methanol inside aged southern tropical to mid-latitude biomass burning plumes using the ACE-FTS instrument, Atmos. Chem. Phys., 6, 3463-3470, doi:10.5194/acp-6-3463-2006, 2006.

González Abad, G., Bernath, P. F., Boone, C. D., McLeod, S. D., Manney, G. L., and Toon, G. C.: Global distribution of upper tropospheric formic acid from the ACE-FTS, Atmos. Chem. Phys., 9, 8039-8047, doi:10.5194/acp-9-8039-2009, 2009.

Harrison, J. J. and Bernath, P. F.: Mid- and long-wave infrared absorption cross sections for acetonitrile, J. Quant. Spectrosc. Rad. Trans., 113, 221-225, 2012.

Kleinböhl, A., Toon, G. C., Sen, B., Blavier, J.-F. L., Weisenstein, D. K., and Wennberg, P. O.: Infrared measurements of atmospheric $\mathrm{CH}_{3} \mathrm{CN}$, Geophys. Res. Lett., 32, L23807, doi:10.1029/2005GL024283, 2005.
Li, Q., Jacob, D. J., Yantosca, R. M., Heald, C. L., Singh, H. B., Koike, M., Zhao, Y., Sachse, G. W., and Streets, D. G.: A global three-dimensional model analysis of the atmospheric budgets of $\mathrm{HCN}$ and $\mathrm{CH}_{3} \mathrm{CN}$ : Constraints from aircraft and ground measurements, J. Geophys. Res., 108, 8827, doi:10.1029/2002JD003075, 2003.

Livesey, N. J., Waters, J. W., Khosravi, R., Brasseur, G. P., Tyndall, G. S., Read, W. G.: Stratospheric $\mathrm{CH}_{3} \mathrm{CN}$ from the UARS Microwave Limb Sounder, Geophys. Res. Lett., 28, 779-782, doi:10.1029/2000GL012144, 2001.

Livesey, N. J., Fromm, M. D., Waters, J. W., Manney, G. L., Santee, M. L., and Read, W. G.: Enhancements in lower stratospheric $\mathrm{CH}_{3} \mathrm{CN}$ observed by UARS MLS following boreal forest fires, J. Geophys. Res., 109, D06308, doi:10.1029/2003JD004055, 2004.

Livesey, N. J., Read, W. G., Froidevaux, L., Lambert, A., Manney, G. L., Pumphrey, H. C., Santee, M. L., Schwartz, M. J., Wang, S., Cofield, R. E., Cuddy, D. T., Fuller, R. A., Jarnot, R. F., Jiang, J. H., Knosp, B. W., Stek, P. C., Wagner, P. A., and Wu., D. L.: Earth Observing System (EOS) Aura Microwave Limb Sounder (MLS) Version 3.3 Level 2 data quality and description document, Tech. Rep. JPL D-33509, NASA Jet Propulsion Laboratory California, Institute of Technology, Pasadena, California, 91109-8099, available at: http://mls.jpl.nasa.gov/data/ v3-3_data_quality_document.pdf (last access: 24 October 2012), 2011.

Manney, G. L., Daffer, W. H., Zawodny, J. M., Bernath, P. F., Hoppel, K. W., Walker, K. A., Knosp, B.W., Boone, C., Remsberg, E. E., Santee, M. L., Harvey, V. L., Pawson, S., Jackson, D. R., Deaver, L., McElroy, C. T., McLinden, C. A., Drummond, J. R., Pumphrey, H. C., Lambert, A., Schwartz, M. J., Froidevaux, L., McLeod, S., Takacs, L. L., Suarez, M. J., Trepte, C. R., Cuddy, C. D., Livesey, N. J., Harwood, R. S., and Waters, J. W.: Solar occultation satellite data and derived meteorological products: Sampling issues and comparisons with Aura Microwave Limb Sounder, J. Geophys. Res., 112, D24S50, doi:10.1029/2007JD008709, 2007.

Montzka, S. A., Reimann, S. (Coordinating Lead Authors), Engel, A., Krüger, K., O’Doherty, S., Sturges, W. T., Blake, D. R., Dorf, M., Fraser, P., Froidevaux, L., Jucks, K. W., Kreher, K., Kurylo, M. J., Mellouki, A., Miller, J., Nielsen, O.-J., Orkin, V. L., Prinn, R. G., Rhew, R., Santee, M. L., Stohl, A., and Verdonik, D.: Ozone-Depleting Substances (OESs) and Related Chemicals, Chapter 1 in Scientific Assessment of Ozone Depletion: 2010, Global Ozone Research and Monitoring Project-Report No. 52, World Meteorological Organization, Geneva, Switzerland, 516 pp., 2011.

Nassar, R., Bernath, P. F., Boone, C. D., Manney, G. L., McLeod, S. D., Rinsland, C. P., Skelton, R., and Walker, K. A.: ACE-FTS measurements across the edge of the winter 2004 Arctic vortex, Geophys. Res. Lett., 32, L15S05, doi:10.1029/2005GL022671, 2005.

Plumb, R. A. and Ko, M. K. W.: Interrelationships between mixing ratios of long-lived stratospheric constituents, J. Geophys. Res., 97, 10145-10156, 1992.

Pumphrey, H. C., Santee, M. L., Livesey, N. J., Schwartz, M. J., and Read, W. G.: Microwave Limb Sounder observations of biomassburning products from the Australian bush fires of February 2009, Atmos. Chem. Phys., 11, 6285-6296, doi:10.5194/acp-116285-2011, 2011. 
Rinsland, C. P., Sharpe, S. W., and Sams, R. L.: Temperaturedependent infrared absorption cross sections of methyl cyanide (acetonitrile), J. Quant. Spectrosc. Rad. Trans., 96, 271-280, 2005.

Rothman, L., Jacquemart, D., Barbe, A., Benner, C. D., Birk, M., Brown, L. R., Carleer, M. R., Chackerian Jr., C., Chance, K., Coudert, L. H., Dana, V., Devi, V. M., Flaud, J.-M., Gamache, R. R., Goldman, A., Hartmann, J.-M., Jucks, J. W., Maki, A. G., Mandin, J.-Y., Massie, S. T., Orphal, J., Perrin, A., Rinsland, C. P., Smith, M., Tennyson, J., Tolchenov, R. N., Toth, R. A., Vander Auwera, J., Varanasi, P., and Wagner, G.: The HITRAN 2004 molecular spectroscopic database, J. Quant. Spectrosc. Radiat. Transfer, 96, 193-204, 2005.

Sanhueza, E., Holzinger, R., Kleiss, B., Donoso, L., and Crutzen, P. J.: New insights in the global cycle of acetonitrile: release from theocean and dry deposition in the tropical savanna of Venezuela, Atmos. Chem. Phys., 4, 275-280, doi:10.5194/acp-4-275-2004, 2004.

Schneider, J., Bürger, V., and Arnold, F.: Methyl cyanide and hydrogen cyanide measurements in the lower stratosphere, J. Geophys. Res., 102, 25501-25506, 1997.
Singh, H. B., Salas, L., Herlth, D., Kolyer, R., Czech, E., Viezee, W., Li, Q., Jacob, D. J., Blake, D., Sachse, G., Harward, C. N., Fuelberg, H., Kiley, C. M., Zhao Y., and Kondo, Y.: In situ measurements of $\mathrm{HCN}$ and $\mathrm{CH}_{3} \mathrm{CN}$ over the pacific ocean: Sources, sinks and budgets, J. Geophys. Res., 108, 8795, doi:10.1029/2002JD003006, 2003.

Tereszchuk, K. A., González Abad, G., Clerbaux, C., Hurtmans, D., Coheur, P.-F., and Bernath, P. F.: ACE-FTS measurements of trace species in the characterization of biomass burning plumes, Atmos. Chem. Phys., 11, 12169-12179, doi:10.5194/acp-1112169-2011, 2011.

Tereszchuk, K. A., Moore, D. P., Harrison, J. J., Boone, C. D., Park, M., Remedios, J. J., Randel, W. J., and Bernath, P. F.: Observations of peroxyacetyl nitrate (PAN) in the upper troposphere by the Atmospheric Chemistry Experiment-Fourier Transform Spectrometer (ACE-FTS), Atmos. Chem. Phys., 13, 5601-5613, doi:10.5194/acp-13-5601-2013, 2013.

Volk, C. M., Elkins, J. W., Fahey, D. W., Dutton, G. S., Gilligan, J. M., Loewenstein, M., Podolske, J. R., Chan, K. R., and Gunson, M. R.: Evaluation of source gas lifetimes from stratospheric observations, J. Geophys. Res., 102, 25543-25564, doi:10.1029/97JD02215, 1997. 